\title{
¿FUE JOHN STUART MILL UN AUTÉNTICO DEMÓCRATA?
}

\author{
Bárbara Baldi \\ Universidad de Córdoba, España \\ barbara80156@gmail.com
}

\begin{abstract}
Resumen / Abstract
Los conceptos de democracia y de gobierno representativo están inevitablemente conectados y vinculados entre ellos, y uno de los principios fundamentales de la democracia representativa es el principio de mayoría. Este articulo es una aproximación a la teoría de John Stuart Mill sobre el gobierno representativo en relación con el principio de mayoría y bajo su perspectiva elitista.

Mill consideró el sistema representativo el modelo político más eficaz, aunque quiso subrayar los puntos críticos y los posibles desvíos negativos de la democracia y, en particular, el riesgo de una dictadura de la mayoría y el contextual aislamiento político de las minorías. El filósofo inglés propuso un ideal de democracia basado sobre el mandato representativo que supone la independencia del representante si bien una independencia restringida y condicionada. Por otra parte, insistió sobre la importancia de que cada ciudadano fuese educado en la conciencia pública y se dejase influenciar por los hombres más cultos y iluminados de la comunidad.
\end{abstract}

PalABRAS ClaVE: democracia, representación política, mayoría, elitismo, interés general.

\section{WAS JOHN STUART MILL AN AUTHENTIC DEMOCRATIC PHILOSOPHER?}

Democracy and representative government are two interwoven and interconnected concepts and one of the most significant principle of representative democracy is the principle of majority. This study is an approach to the John Stuart Mill's democracy theory about the representative government in connection with the principle of majority and under his elitist perspective.

Mill considered representative government as the most effective politic model, however he also highlighted the critical points y the negative posible drifts of democracy, especially the risk of a dictatorship of the majority and the resulting political isolation of the minorities. The English philosopher proposed an ideal of democracy based on the representative mandate thet implies the independence of the representantive, although it would be a conditioning and limited indipendence. On the other hand, he also highlighted the importance for every citizen to be educated to the public consciuosness and influenced by the most knowledgeable people.

KEY WORDS: democracy; politic representation; majority; elitism; public interest. 


\section{Utilitarismo y liberalismo, fuentes ideológicas de J.S. Mill}

R⿴囗十 Norberto Bobbio señala que la historia del liberalsocialismo podría comenzar con John Stuart Mill (Bobbio 2003, p. 387)ํ․ El filósofo británico empezó a alejarse de la escuela utilitaria del liberalismo inglés influenciado por autores como Comte y Tocqueville, quienes le transmitieron múltiples desilusiones sobre la exaltación radical del sistema democrático y sobre los posibles desvíos de éste hacia una tiránica uniformidad de opinión (Negro Pavón 1985, p. XI). Efectivamente, lo que teme Mill es la tiranía de la mayoría y el aniquilamiento de las minorías, peligros reales de la democracia que amenazan, además, una representación política auténtica. Es decir, la opinión publica dominante puede implicar la disolución de opiniones contrarias, como si respetar la opinión dominante fuese una regla no escrita de la democracia, impuesta por la conciencia de que, de todas formas, la mayoría tiene derecho a imponerse y, por lo tanto, disentir no tendría sentido ${ }^{2}$. La nivelación de opiniones y la pérdida de capacidad de crítica y de evolución social en general, dicho de otra forma, la pérdida de la excelencia ${ }^{3}$ son el triunfo de lo común y de lo banal. Pero, sobre todo, no es solo el individuo que pierde relevancia sino que es la misma sociedad condenada al esclavismo.

Según Galvao de Sousa, el "dogma de la igualdad distorsiona la estructura social porque no deja espacio para grupos de naturaleza distinta, los cuerpos intermedios" (Galvao de Sousa 2011, p. 79). A propósito del dogma de la igualdad, Mill, se expresa de manera clara:

(...) cuando la igualdad de condiciones habrá llegado al nivel en el que se encuentra ahora en América, y ya no habrá ningún poder intermedio entre monarca y multitud, cuando no quedarán individuos o clases capaces de poner obstáculos a la voluntad de gobierno, entonces, si el pueblo no será capaz de gobernar, el monarca se convertirá en un autócrata perfecto parecido igual que en el despotismo asiático. Ahí donde todos son iguales, o son todos libres o son todos esclavos (Mill 1840).

La igualdad de condiciones supone, entonces, que o no haya algún tipo de autoridad $\mathrm{y}$ todos los individuos sean igualmente libres porque, de otra manera, la autoridad así formada será necesariamente despótica y el pueblo completamente esclavo del

1 En el mismo sentido van las perentorias definiciones de Shumpeter sobre John Stuart Mill: "Mill fue exactamente lo que se dice un socialista reformista" (Shumpeter 1971).

2 Esta consideración sobre la opinión pública dominante es mayormente presente en Tocqueville que advierte: "Cuando, como suele suceder, la libertad de prensa se combina con la soberanía del pueblo, se observa que la mayoría a veces decide claramente a favor de una opinión. Luego, la opinión contraria no tiene mayores posibilidades de hacerse oír; (...) La libertad de prensa existe de nombre, pero en los hechos la censura reina, una censura mil veces más poderosa que la que se ejerce desde el poder" (Tocqueville 1990, p. 183).

3 Esta misma posición la sugiere Ortega y Gasset que, de manera parecida auspicia una sociedad culta y despierta que mire a la excelencia mediante la guía de las guías de una minoría selecta (Ortega y Gasset 1922, p. 61). 
poder. Ya Tocqueville había observado que la igualdad no era condición ni necesaria ni suficiente para la democracia. En efecto, la igualdad de condiciones amenazaba el valor fundamental de la libertad en el momento en el que fomentaba la tiranía de la mayoría o en otras palabras, la excesiva centralización del poder en manos de la mayoría (Tocqueville 1990; Dahl 2000; Kelsen 1934, p. 82). Dalmacio Negro Pavón señala que la concepción de libertad de Mill es parecida a la de Hobbes, ambos la conciben como un poder, de hecho Mill afirma que libertad consiste en "arreglos que neutralicen los obstáculos naturales a la libertad individual” (Negro Pavón 1968, p. 149).

Desde otra perspectiva, la opinión publica no puede generarse dentro de la multitud. En efecto, según Ortega y Gasset "el pueblo no piensa: aquella porción suya que podría servirle de cerebro es precisamente lo que llamamos élite, aristocracia, los pocos y que con tanto cuidado solemos aislar frente a los muchos, al vulgo, al demos (...) Como del pueblo tiene que salir todo, es menester que salga también lo que no es pueblo: los escogidos ... podría definirse al pueblo como lo indeterminado histórico a determinar por la cultura" (Ortega y Gasset 1908, p. 195). La posición de Ortega parece más contundente que la de Mill, aunque, de facto, ambos subrayan una cuestión: la multitud, la mayoría de ciudadanos abstractamente considerada, necesita de una minoría selecta que no pertenece a alguna clase social determinada, sino que destaca, dentro de la sociedad por cultura y talento. Un sistema político que no considere fundamental la aportación de esta minoría es un sistema político débil y la democracia no puede suponer un poder ilimitado de la mayoría, que es lo mismo que decir de la masa.

El otro dilema de John Stuart Mill era encontrar un sistema político capaz de evitar la centralización del poder ${ }^{4}$ en una única clase social impuesta sobre las demás. Así, el punto de partida de su teoría lo encontraríamos en el establecimiento de la igualdad de condiciones de todos los actores políticos como característica dominante en un sistema democrático. En este contexto, podemos colegir que las dificultades del éxito de la democracia en Europa nacieron, precisamente, de una tradición de poderes fuertes como fueron las aristocracias o las antiguas oligarquías.

El filósofo británico, profundamente influenciado por los trabajos de Jeremy Bentham, y que como es sabido no aceptó el desarrollo iusnaturalista del estado de naturaleza propedéutico al contrato social, señala que:

(...) el estado de la sociedad contemplado por Rousseau, en el cual los hombres vivieron juntos sin un gobierno, puede que nunca haya existido, y de hecho si tal situación haya o no existido no supone ninguna consecuencia. La cuestión no es si ha existido o no un estado de naturaleza, sino si resultaría útil suponer su existencia hipotéticamente (Mill, UA, 1832).

4 Tocqueville, a propósito de la excesiva centralización del poder observó que los gobiernos post revolución tienen un poder inmenso que aniquila y atrae así todas "las parcelas de autoridad y de influencia antes dispersas en una serie de poderes secundarios (...)". (Tocqueville 1988, p. 57). 
Mill explica que citar el estado de naturaleza, aunque solo de forma hipotética, es útil para determinar qué tipo de moral tendría en una sociedad sin leyes. Más allá de la cuestión política del gobierno, considera que resulta útil indagar sobre la cuestión moral y añade:

Con respecto al contrato social (aunque se considere como una pura ficción que no puede llevar ninguna argumentación válida) y a su doctrina relativa a los derechos del hombre inalienables y imprescriptibles, la utilidad de estas consideraciones consiste en el criterio por el cual el poder del soberano, aunque no limitado por leyes, tiene un límite moral que se expresa en la tesis por la cual un gobierno no debería pedir a ninguno de sus gobernados más de lo que él da" (Ibídem).

Mill, que parece convencido de la ficción de una teoría contractualista y un estado de naturaleza, no niega una utilidad de la hipótesis que es dada por una cuestión moral: aunque no haya gobierno ni leyes, la sociedad necesita de un imprescindible elemento de reciprocidad moral. Esto vale también para el soberano que no podrá pretender de sus sujetos más de lo que él mismo da. El principio de utilidad, parece ser, pues, elemento esencial de la sociedad.

\section{Siguiendo con el razonamiento del filósofo británico:}

Si alguien molesta u ofende a algún conciudadano, las consecuencias de lo que la víctima de la ofensa hace como autodefensa tienen que recaer sobre él: de otra manera el gobierno no respeta su propio deber si a cada solicitud de hacer el bien común se limitara a hacer que el gobernado se sienta un perdedor solo por el hecho de ser gobernado y que piense que estaría mejor si el gobierno no existiera. (...)" (Ibídem).

No obstante, la negación de la teoría del contrato social y del estado de naturaleza por parte de Mill y su justificación de la existencia de un gobierno que debe proteger y garantizar la incolumidad de cada hombre parece argumentada según los criterios de Hobbes. De hecho, la necesidad de un gobierno nace naturalmente conforme al progreso de la sociedad, progreso cultural y racional. Entendemos entonces que para Mill el progreso de la sociedad se desarrolla con las cualidades humanas, las virtudes, la inteligencia de los seres humanos que la componen y que respiran la atmósfera superior de una opinión pública virtuosa e ilustrada (Mill 1985, p. 21).

Mill reafirma que la existencia de un gobierno, un poder al que el pueblo acepta someterse, es concebible solo en el caso de que este gobierno se considere un beneficio por parte de los gobernados. El sujeto gobernado debe sentir que merece la pena someterse, que la reducción de su libertad es compensada por otros beneficios y en este sentido el deber moral del gobierno es el de procurar beneficios a sus gobernados. La teoría de los derechos del hombre tiene la utilidad, en consecuencia, de subrayar el aspecto moral del poder gubernamental. Si faltara en esto, el pueblo estaría legitimado a cambiarlo porque se perdería su elemento esencial, el elemento de utilidad. 


\section{Aproximación a la teoría de J. S. Mill sobre el mandato representativo}

Mill consideraba necesaria la representación política al punto de tratarla como un axioma; de hecho, "así como el género humano en un estado de sociedad necesita de un gobierno, porque sin él cualquier hombre más fuerte tendría la posibilidad de oprimir su vecino más débil; así el género humano en un estado de gobierno necesita de representación popular, porque sin ella los que ejercen poderes de gobierno podrían oprimir a los otros individuos" (Mill, OL, 1859). Una sociedad necesita de un gobierno que garantice protección a los individuos, pero el gobierno debe ser un gobierno representativo para que todos puedan participar, aunque mediatamente, en la gestión de la cosa pública.

Esta es la esencia de la representación popular: que el pueblo no gobierne personalmente sino que elija sus propios representantes, los cuales serán elegidos entre todos los más dignos ${ }^{5}$, los que gozan de la confianza de la mayoría del pueblo ${ }^{6}$ y solo hasta que esta confianza perdure. "La soberanía del pueblo es esencialmente una soberanía delegada. El gobierno lo hacen pocos para la ventaja de muchos" (Mill p. 1832). Desde un primer momento, pues, la representación política milliana parece coincidir con un modelo de representación indirecta.

Los representantes gobiernan, pero el mecanismo de elección está basado en la confianza, y en este sentido, el representante es un mandatario elegido para hacer el bien común. Se trata de un mandato de confianza, lo cual supone que después de la elección el representante es libre y sobre todo independiente para decidir por encima de los intereses de parte. Sin embargo, se trata siempre de mandato, es decir, el vínculo que conecta el representante con el representado es un vínculo de mandato y, por tanto, aquella confianza habrá que respetarla debiendo actuar los representantes con un gran sentido de responsabilidad. De hecho, "nadie está obligado a ser miembro del Parlamento. Los electores no bloquean a un ciudadano particular que anda por calle y lo llevan obtorto collo a St. Stephen 's" (Ibídem). Se trataría, según la tesis de Mill, de un mandato basado sobre dos elementos esenciales: en primer lugar, el sentimiento de confianza de los electores que deberían reconocer y elegir a quienes que pueden presumir de una superioridad intelectual reconocible (Mill 1985, p. 143); en segundo lugar, la actitud responsable ${ }^{7}$ de los representantes habida cuenta de que sus funciones deben de ser provechosas para los gobernados.

Mill parece buscar el equilibrio en una representación ideal perfecta que juega entre la confianza de los electores que tienen que fiarse del "hombre capaz" y aprovecharse de

5 En Ortega y Gasset la función de las masas es la de reconocer los mejores, esa minoría selecta más capacitada para guiar y gobernar una nación (Ortega y Gasset 1922 p. 61).

$6 \quad$ Las ideas de Mill sobre el tipo de mandato basado sobre la confianza se parecen mucho al modelo propuesto por Bockenforde: "si la representación formal no tiene que caer en la arbitrariedad, la representación substancial no debe limitarse a la reproducción de la voluntad empírico-natural de los representados" (Bockenforde 1985, p. 257).

Sobre la responsabilidad de los representantes en Mill, véase Urbinati 2006, p. 133. 
su talento y su competencia y, por otra parte, la responsabilidad del representante que debe estar al servicio de la nación sin ninguna influencia de intereses no identificados con el bienestar general de la comunidad (Mill 1985, p. 69).

La confianza conlleva el hecho de que el representante, elegido por sus cualidades morales e intelectuales, esté libre de gobernar como considere oportuno. En el artículo Pledges ("Compromisos"), Mill explica su propia concepción de mandato y en qué consiste el compromiso del representante. Se trata de un representante libre pero responsable. Subsiste un vínculo continuo con sus electores, pero este vínculo es un vínculo de confianza esencialmente libre. Esto es, un mandato representativo responsable. En palabras del propio J. S. Mill:

Si se puede decir que hubiera una culpa moral de los gobernantes que intentaran conservar su autoridad de manera contraria a las inclinaciones del pueblo, también se puede decir que el pueblo tiene el derecho de cambiar a sus gobernantes y todo eso sin alguna contradicción o abuso de lenguaje (Mill, UA, 1832).

Como acabamos de ver, Mill pone las bases para explicar la relación entre gobernantes y gobernados mediante los conceptos de derecho y deber y, sobre todo, bajo una perspectiva "moral". En este sentido propone una relación de reciprocidad moral condicionada por el buen gobierno/obediencia, mal gobierno/cambio de gobierno. El buen gobierno, que es entonces un deber moral de los gobernantes y del que depende la obediencia de los gobernados consiste en gobernar conforme a las "inclinaciones" del pueblo. Es decir, que el pueblo tiene el deber moral de obedecer solo en el caso que el gobierno corresponda a sus aspiraciones, que es lo mismo que decir a la voluntad del pueblo; si así no fuera, no solo no habría ningún deber de obediencia sino que un gobierno contrario a la voluntad del pueblo podrá ser cambiado por él mismo y este cambio es un derecho moral ${ }^{8}$ de los gobernados.

\section{Del buen gobierno para Mill. Mayorías, minorías y fuerzas de oposición}

En un ensayo de 1838 sobre la filosofía política de Bentham, Mill advierte que son tres las preguntas fundamentales sobre la teoría del gobierno: primero, a qué autoridad debería someterse el pueblo para su bienestar; segundo, de qué manera se puede inducir al pueblo a obedecer a esta autoridad, y por último, qué medios se pueden utilizar para controlar eventuales abusos del poder (Mill 1999, p. 85).

8 A propósito de moral, el mismo Mill señala que la cuestión del mandato representativo es una cuestión que no se refiere a la legislación de la constitución sino que es una cuestión de "moralidad constitucional". Con esto, el filósofo quiere poner en relieve que con respecto al mandato representativo solo un juicio prudente, tanto de los electores a la hora de votar cuanto de los representantes a la hora de decidir, puede garantizar la mejor representación política (Mill 1985, p. 138). 
Las primeras dos cuestiones dependen, para Mill, del grado de civilización y del progreso cultural que tenga un pueblo y su particular propensión a mejorar. La tercera cuestión es más objetiva y definida y a ella contesta con la única posible respuesta: responsabilidad. En efecto, para Mill, el buen gobierno es posible solo en cuanto exista responsabilidad hacia personas que tienen un interés específico y reconocible que debe coincidir con la perspectiva del fin. En otras palabras, para Mill, el interés se puede identificar con el buen gobierno o sea, con el bien común. Si para Bentahm el buen gobierno y consecuentemente el bien común se encuentran en la decisión de la mayoría, Mill advierte que solo cuando el interés es de la comunidad y no solo de una parte de ella se puede hablar de buen gobierno.

Mill justifica el gobierno representativo con la consideración que todos los hombres deberían interesarse y poder participar a las cosas del gobierno, "privad de que haga algo por su país y se cuidará de él para nada" (Mill 1985, p. 32), sin embargo, la mayoría del pueblo tiene una conciencia de dilettanti, como el saber mecánico de las personas que nunca han manejado un útil, y por esta razón necesita de representantes.

Si el gobierno representativo consiste en otorgar poder a una mayoría numérica ${ }^{9}$, la realidad política no puede ser la del bien común, puesto que para Mill la mayoría numérica de cada sociedad no puede ser formada por personas de la misma posición social y con mismos objetivos, parcialidades, pasiones y prejuicios ${ }^{10}$. Mill no niega que dar el poder a la mayoría sea la única solución, no la más justa, pero sí la menos injusta, sin embargo, si la mayoría no tiene una oposición fuerte, la libertad y sobre todo la posibilidad de progreso de un pueblo se verán cortadas y destinadas al declive.

Para Mill, el principio de mayoría podía transformarse en despotismo de la mediocridad. En otras palabras, en el desprecio de una "minoría de individuos que poseen la densidad vital que se precisa para entusiasmar a las masas" (Ortega y Gasset 1922, p. 56), como diría Ortega y Gasset. Mill considera que la democracia y la representación no pueden reducirse a un cálculo aritmético, por esto el principio de mayoría no puede ser fundamento de la democracia. La fuerza de la oposición sería el único instrumento de equilibrio democrático, pero ¿es razonable pensar en poder contener el inconmensurable poder de la mayoría? Según Ortega, "nada abusa con mayor claridad la fisionomía del presente como el hecho de que vayan siendo tan pocos los países donde existe la oposición. En casi todos una masa homogénea pesa sobre el poder público y aplasta, aniquila todo grupo opositor"(Ortega y Gasset 2011, p. 141).

9 Sobre el principio de mayoría y su dificultad de justificarlo dentro de un modelo democrático, Kelsen señala que, en efecto, dicho principio es "un contrasentido de la política". El filósofo, aunque admite que el principio de mayoría absoluta es la aproximación relativamente mayor a la idea de libertad, subraya también cómo es imposible hablar de una representación auténtica puesto que incluso los que pertenecen a la mayoría quedan sujetos a una voluntad ajena en el momento en el que cambian su orientación, puesto que el orden social impone "haz esto" pero no cuando y como quieras (Kelsen 1934, p. 21).

10 Mill sostuvo el principio de la representación proporcional de las minorías determinado según la conocida fórmula de Hare. 
Toda vez que el amor por el poder hace demasiado difícil convivir con el enemigo, el amor por el poder es cosa distinta, advierte Mill, del amor por la libertad. El amor por el poder es egoísta (selfish) (Mill 1862), mira al interés particular y es la pasión humana más dañina porque ejercer un poder sobre otros para intereses personales es exactamente lo contrario que el amor por la libertad.

Mill observa que el antagonismo sistemático es la única condición bajo la cual la sociedad puede desarrollarse y mantenerse estable (Mill 1845); es pues el conflicto de la oposición contra el poder gobernante, conflicto que, además, debería ser sistemático, que garantiza el progreso de la sociedad (Mill 1985, p. 15) ${ }^{11}$.

Para Burdeau, puesto que la democracia gobernante es una democracia de fuerzas, en ella la mayoría es un valor en sí; no obstante, esta mayoría "tiene que actuar de tal forma que su actitud no comprometa en absoluto las oportunidades de la oposición" (Burdeau 1955, p. 8). Según el jurista francés, la mayoría más que tolerar la disidencia de la oposición debería suscitarla porque "en nombre de la libertad de todos debe soportar que la libertad de los demás sirva para ahogar la suya propia” (Ibídem). Sin embargo, el mismo Burdeau admite que no hay instrumentos constitucionales eficaces que obliguen la mayoría a actuar de esta manera. En efecto, “como la voluntad del pueblo no existe antes de ser expresada por los órganos del Estado, ninguna institución constitucional puede prevalerse de representar, mejor que las otras, el deseo popular. (...) El poder -aquí- puede contener impunemente al poder" (Ibídem).

Mill, indudablemente influenciado por Tocqueville, insiste en la necesidad de poner límites a la supremacía del principio de mayoría que, por su naturaleza, tiende a ser ilimitado y hace que la disidencia a tal poder absoluto sea imposible; en este sentido habla de dictadura de la mayoría. Si bien Tocqueville se expresa categóricamente en contra de poder ilimitado del principio de mayoría y declara que lo más detestable es que en materia de gobierno la mayoría tiene derecho a hacerlo todo (Tocqueville 1990, p. 236), para Mill el peligro del despotismo de la mayoría se limita a través de la educación de los ciudadanos (Negro Pavón 1968) ${ }^{12}$ y a través de la virtud pública. Mill propone como remedio a la mediocridad a la que el principio de mayoría podría llegar, una minoría culta dentro de la sociedad, una élite excelente que consiga captar el interés general en el respeto de todas las opiniones.

La minoría culta debería ejercer, entonces, una acción pedagógica tal como señaló Ortega y Gasset, que define dicha función educadora como un "movimiento creador de toda sociedad, la ejemplaridad de unos pocos se articula en la docilidad de otros muchos. El resultado es que el ejemplo cunde y que los inferiores se perfeccionan en

11 Mill cita la clasificación de Coleridge sobre la sustancia del bien colectivo entendido como permanencia y progresión (orden y progreso según la fraseología francesa).

12 "Su finalidad era educar a las mayorías en las ideas que él creía verdaderas y de acuerdo con los tiempos. (...) La tecnocracia ha tenido así en Mili a uno de sus mejores expositores, tal vez porque el filósofo inglés no penetró en la verdadera naturaleza de la técnica ni de la ciencia” (Negro Pavón 1968, p. 137). 
el sentido de los mejores"(Ortega y Gasset 1922, p. 64). La ausencia o escasez de "los mejores" dicta las pautas históricas de una sociedad incapaz de crecer, de desarrollarse, y esta ausencia es el resultado de una acción de aniquilamiento de los individuos más "privilegiados" por parte de las masas.

La voluntad general no se corresponde a la voluntad de todos, pues la primera persigue el interés común, mientras que la segunda persigue el interés privado; en otras palabras, para Mill, la voluntad general no se puede hallar en la voluntad de la mayoría, puesto que los "intereses siniestros" incumben en contra del interés general. El interés colectivo no es entonces el interés de la mayoría de los ciudadanos; es aquel tipo de interés que perjudica el cuerpo colectivo como tal, o sea, la sociedad en su conjunto.

En este sentido, Benjamin Constant, comentando el origen de la sociedad y el vínculo entre los hombres señala que "los hombres necesitan para que se asocien recíprocamente sus destinos algo más que el interés. Necesitan una opinión. Necesitan moral. El interés tiende a aislarle porque ofrece a cada uno la oportunidad de ser, solo, más feliz o más hábil" (Constant 1988, p. 22). Es, entonces el mismo concepto de interés que, por su naturaleza, no puede ser general, pues el interés, en sí, es siempre particular; lo que, al contrario vincula un conjunto de personas es, para Constant, una opinión común y la moral.

Constant, en su crítica a la voluntad general de Rousseau, pone el problema fundamental de la limitación del poder y advierte que "cuando se establece que la soberanía popular es ilimitada, se crea y se introduce caprichosamente en la sociedad humana un grado de poder demasiado grande en sí mismo, y eso es malo, independientemente de quien lo posea" (Constant 1989, p. 9). La soberanía popular, para el pensador francés, existe solo de manera limitada y relativa; de hecho: "es a la cantidad de poder y no a quienes son sus depositarios a quien hay que acusar" (Ibídem). Limitar el poder de la soberanía popular significa, principalmente, afirmar que el consentimiento de la mayoría no legitimaría en sí todo tipo de acto porque esto afectaría a la libertad y a los derechos individuales.

La cuestión fundamental para Mill es la garantía de un buen gobierno, y señala que "la idea de una democracia racional no significa que el pueblo gobierne, sino que tenga la seguridad de un buen gobierno. Esta seguridad no la puede tener por ningún otro medio que no sea el retener en sus propias manos el último control" (Mill 2005, p. 257); si se renuncia a este control del poder se acaba en la tiranía, advierte Mill, puesto que una clase de gobierno irresponsable no puede hacer otra cosa que sacrificar al pueblo para perseguir su interés particular. El pueblo no puede gobernar directamente aunque quede siendo el dueño: "tiene que ser el dueño, pero un dueño que emplea sirvientes más hábiles que él mismo" (Ibídem). Pero esto por sí mismo no es suficiente, puesto que para garantizar un buen gobierno, el pueblo, que es dueño, debe tener el control último de estos "sirvientes" y el control último es el poder de revocación.

Ya Constant insistió en la necesidad de limitar los poderes de los representantes también mediante revocación para evitar una demagogia desenfrenada y turbulenta; "una asamblea que no puede ser refrenada ni contenida es, por los miembros que la 
componen, el más ciego de todos poderes en su movimiento y el más imprevisible en sus resultados" (Constant 1989, p. 57).

También para Mill es importante subrayar que el poder de los gobernantes no puede ser absoluto. El ejercicio del poder tiene que ser limitado. La limitación del poder es necesaria para impedir el abuso y lo único que puede limitar la tiranía de la mayoría (Mill 1985, p. 84) (3) $^{13}$ ser una oposición fuerte y activa que intervenga para contribuir en cumplir el interés colectivo:

Pongamos que el gobierno se conforme con la voluntad del pueblo y nunca ejerza coacción que no sea completamente de acuerdo con la opinión del pueblo, lo que yo contesto es ese mismo poder del pueblo, que sea directo o mediante el gobierno. Ningún gobierno ni el mejor ni el peor puede considerar legítimo este poder de coacción. Aun cuando la comunidad entera excepto una sola persona tuviese la misma opinión, y aquella persona tuviese la opinión opuesta, no por eso la humanidad podría no considerarla (Mill 1999, p. 84) ${ }^{14}$.

Mill llega a considerar la oportunidad de otorgar a los ciudadanos más iluminados la posibilidad de que sus votos valgan más que otros (Negro Pavón 1969 p. 133) ${ }^{15}$. Aunque el filósofo inglés tenga claro que un sistema democrático se funda sobre el principio según el cual cada opinión merezca la misma atención para llegar a un resultado que se conforme al interés general, "hombre por hombre la minoría debe hallarse tan completamente representada como la mayoría. Sin esto no hay verdadera representación del Gobierno" (Mill 1985, p. 83) ${ }^{16}$ y a la hora de explicar cómo se puede obtener tal resultado deseable, cae en una difícil contradictoria posición elitista: "Ninguno, si no es un necio, y un necio de especie particular, puede sentirse ofendido porque se reconozca que hay otros cuya opinión, y aun cuyo deseo, deben ser mas atendidos que su deseo y su opinión” (Mill 1985, p. 107) solo quedarían representados los intereses

13 Mill aclara que la mayoría numérica en realidad es minoría: “(...) La democracia así constituida no alcanza su fin ostensible, el dar siempre el poder a la mayoría numérica; hace algo muy diferente: lo entrega a una mayoría de la mayoría que quizá no sea, y frecuentemente no es, más que una minoría de la colectividad” (Mill 1985, p. 84).

14 Mill continúa: "Pongamos que el Gobierno sea, de verdad, lo mismo que el pueblo, y que nunca pensaría ejercer un poder de coacción sin que sea de acuerdo con la opinión que él considera que venga por el pueblo. Bueno: lo que yo contesto es que el pueblo tenga derecho de ejercer aquella coacción, no importa si por sí mismo o a través del Gobierno. Es aquel poder en sí que es ilegítimo (...) Aun cuando toda la humanidad, excepto una sola persona, tenga una determinada opinión y aquella única persona tuviese la opinión contraria, no por esto la humanidad podría”(Mill 1999, p. 84).

15 Para Dalmacio Negro, Mill acaba siendo un antidemocrático "a la larga sus propias ideas se volvieron contra la democracia que creía defender, porque la razón, manejada colectivamente, se torna irracional". Véase también, Jiménez Sánchez 2004.

16 Hanna F. Pitkin considera que para Mill los representantes tienen la función principal de controlar y vigilar los actos de gobierno y sobre todo dar voz a todas las opiniones, de manera que todas las posiciones críticas diferentes salgan a la luz (Pitkin 1985, p. 70). 
y cualidades peculiares de la masa, siquiera fuese en la más alta expresión, mientras que, por el contrario, la cualidad que por su naturaleza no pertenece a la multitud y que únicamente puede encontrarse en una minoría (...) que forma el natural suplemento y límite de la masa"( Bluntschli 1880, p. 70). Bluntschli llega a afirmar que el sufragio universal, entendido como igual derecho de voto para todos, hace que prevalezca la fuerza de la "tosca e ignorante" (Bluntschli, p. 66) aunque numerosa muchedumbre sobre las clases cultas de la sociedad.

Son los más sabios, esta clase intelectual, quienes deberían gobernar educando a la masa hacía la democracia. En la existencia de una clase que no necesita trabajar podemos ver el mayor remedio para todas las desventajas de la democracia, porque el único gobierno capaz de asegurar el máximo bien a la comunidad necesita llegar a entender una concepción iluminada sobre la esencia del bien colectivo, y por esto los mejores gobernantes han de ser los más cultos y capaces de la sociedad (Negro Pavón $1968)^{17}$; de hecho, para Mill, "el honor y el mérito del hombre medio es el de ser capaz de seguir estas iniciativas y adherir íntimamente a las cosas sabias y nobles y dejarse guiar hacia ellas con ojos abiertos" (Mill 1859) ${ }^{18}$.

Hanna Fenichel Pitkin considera que representar es actuar en interés de los representados de una manera sensible ante ellos (Pitkin 1985, p. 233), esencialmente propone un modelo de representación basado sobre la responsabilidad del representante. El representante es libre, pero, como tiene que ser sensible ante las instancias de sus electores y puesto que es responsable ante ellos, su libertad es, en este sentido, limitada. De hecho: "Así, se puede considerar equivalente gobierno representativo y soberanía popular, lo cual no quiere decir que los votantes decidan de hecho una política legislativa, sino que quiere decir que los gobernantes políticos serían responsables ante los votantes en las elecciones periódicas" (Ibídem). No se trata, entonces de un representante libre tout court, como el auspiciado por Edmund Burke (Burke 1993; Sieyes 1991) puesto que insiste en la referencia a la responsabilidad.

El representante de Mill, como se ha visto previamente, es un representante responsable como lo entiende Hanna Pitkin; de facto, su independencia es condicionada a que haga bien su deber de modo que, en el momento en el que asume una responsabilidad pero no puede llevarla a cabo de manera concienzuda no le queda otra alternativa que dimitir. El representante no solo estaría obligado a probar ante sus electores su actitud a ejercer su cargo sino que también se precisa que las ideas del representante confluyan con las de sus electores, los cuales, en caso de disentimiento incontenible tienen derecho a destituir al diputado. El mandato representativo es un híbrido de confianza y responsabilidad, y según Nadia Urbinati se trata de un estilo de mandato

17 "Sus ideas conducen a la concepción del gobierno como una élite" (Negro Pavón 1969, p. 134).

18 "El honor y la gloria del hombre medio consiste en su capacidad de seguir la iniciativa; de responder interiormente a las cosas sabias y nobles y dejarse guiar por ellas con los ojos abiertos" (Mill, OL, 1859). 
que se podría definir como "advocacy", que se caracteriza por autonomía de juicio y responsabilidad y conexión con los electores (Urbinati 2006, p. 105).

La impostación del sistema político milliano consiste, entonces, en un Parlamento compuesto por un gran número de representantes del pueblo, que tiene la función de discutir, generar opiniones y vigilar, y un gobierno formado, al contrario, por un numero restringido de individuos especialmente capaces, que tiene la función de legiferar y tomar decisiones. En la misma línea, Galvao de Sousa se refiere a las funciones de gobierno y asamblea popular, distinguiendo la representación ante al poder y la representación en el poder, y observa que "representar al mayor número y aprovechar de las élites dirigentes han sido preocupaciones constantes de cuantos anhelan la realización de la idea democrática. Cuanto más amplia sea la representación ante al poder, tanto más perfecta podrá ser la idea democrática. Pero la representación de la sociedad en el poder, para compartir la dirección de la cosa pública, tiene que ser restringida y cuanto más rigurosa sea la selección, más perfecto será el gobierno" (Galvao de Sousa 2011, p. 48). En la misma línea de Mill, para el filósofo brasileño es fundamental distinguir representación y autoridad, los dos conceptos deben ser independientes; de hecho, una cosa es la representación a la que cumple manifestar la variedad del pueblo, otra cosa es el gobierno al que compete, sobre todo, realizar la unidad social.

Cuando Mill explica su posición hacia las funciones de los representantes y del Parlamento deja claro que una colectividad y, consecuentemente, una asamblea numerosa no es idónea para la acción. La función del Parlamento es la de atender que las personas encargadas de decidir sean competentes y acordar el consentimiento final de las medidas y no tiene importancia que los proyectos de leyes sean principalmente redactados por burócratas o expertos no elegidos, puesto que ninguno de esos proyectos se convierte en ley si no ha sido sometido a la discusión de la instancia colectiva elegida efectivamente, lo que convierte a una proposición en una decisión pública, no es la discusión, sino el consentimiento (Manin 1998).

Mill, con su propuesta de voto desigual, quiere evitar la tiranía de la mayoría numérica que pondría al margen la clase más culta que sería más capaz cultural y moralmente de elegir lo mejor para el bienestar colectivo (Sartori 2011). Mill lo especifica más veces y llega a afirmar que "debe procurarse que la participación en todo sea tan grande como lo permita el grado de cultura de la comunidad; y que, finalmente, no puede exigirse menos que la admisión de todos a una parte de la soberanía"(Mill 1985, p. 43). Con estas palabras, Mill aclara que aunque cada hombre adulto tiene que tener voz en el gobierno (Mill, TOPR,1859), hay que considerar que una cosa es que cada uno pueda participar, y a nadie se quite este derecho moral por el que siempre se tiene que luchar, pero otra cosa es afirmar que todas las voces hayan de tener el mismo peso. Cuando Mill afirma que uno de los rasgos más desfavorable de las instituciones americanas se halla en la idea de que todos los hombres son iguales, que la clase culta tiene el mismo peso social de la clase ignorante, lo explica por la razón que " la posición que estimula más vivamente el desarrollo de la inteligencia es la conquista del poder no el poder conquistado (...)" (Mill 1985, p. 111). El derecho al sufragio debe descansar para Mill en el valor personal y puesto que la clase culta se encuentra 
numéricamente inferior, es razonable, para el filosofo inglés, que se le asigne un grado de influencia mayor ${ }^{19}$. Dirá Ortega que lo más interesante de John Stuart Mill es su preocupación por la homogeneidad de mala clase que veía crecer en todo Occidente (Ortega y Gasset 2011, p. 61).

Si para Mill la sociedad se tiene que educar en la democracia para que exista un buen gobierno, el valor de un gobierno se mide por el valor que le otorga la sociedad que lo ha elegido:

(...) las instituciones representativas tienen también poco valor y pueden ser simples instrumentos de tiranía o de intriga cuando la masa de los electores no se interesa lo bastante en el gobierno para votar o cuando la mayor parte de los electores, en vez de votar según los motivos del bien público venden sus sufragios o lo dan a instigación de alguna persona influyente cuya simpatía tratan de captarse por razón de conveniencia (Mill 1985, p. 8).

El sufragio universal, elemento esencial de la democracia, puede, según Mill, degenerar en compraventas de votos y perspectivas egoístas, hasta perder cualquier valor democrático.

Dentro de una perspectiva elitista, para Guizot la representación política tenía que reflejar las opiniones de los más expertos y no de todos los individuos por el mismo hecho de existir; "cuando las cosas siguen sus leyes naturales sin mezclarse la fuerza, el poder va a parar en manos de los más capaces, de los escogidos, de aquellos que dirigirán la sociedad a su objeto" (Guizot 1839 p. 113). Los que tienen derecho a votar, para el historiador francés, son los capaces y la capacidad es la condición que otorga el derecho y que consiste en actuar de acuerdo con la razón. A la ley compete la función de identificar y fijar el grado de esta capacidad basándose en la inteligencia y la posición social (Guizot 1839).

Mill insiste en la inutilidad de teorizar como debería de ser un buen gobierno cuando por obra y voluntad de quien tendría que formarlo, ya en su origen se encuentra corrompido y reafirma como solo la educación y el desarrollo de una sociedad capaz de votar según intereses generales y no personales puede ser garantía de buen gobierno. Como producto de la elección de la sociedad, un buen gobierno es responsabilidad de la sociedad misma, no es un mecanismo impuesto sino que se genera dentro de la sociedad. La falta de interés para la cosa pública o la corrupción que conlleva anteponer el interés privado al interés colectivo se traducirá necesariamente en instituciones débiles, en un gobierno inadecuado. Por esto, el conjunto de cultura y moral de la sociedad es la única garantía para un buen gobierno. Para Mill, el malestar de la

19 "Es cierto que lo hacía para preservar a las minorías de la absorción por la mayoría, pero a la vez respondía a sus ideas utilitarias, favorables al gobierno de los expertos, idea que excluye la del sufragio universal, ya que su lógica conduce a la conclusión de que difícilmente el elector será capaz de valorar los méritos del gobernante al convertirse el arte del gobierno en una ciencia esotérica" (Negro Pavón 1969, p. 139). 
sociedad reside en la inmovilización general, en la falta de evolución cultural, en sus palabras "leen las mismas cosas, escuchan las mismas cosas, ven las mismas cosas, van a los mismos sitios, tienen sus esperanzas y sus temores puestos en los mismos objetos, tienen los mismos derechos, las mismas libertades y los mismos medios de reivindicarlas" (Mill, OL, 1859). En esta inmovilización reside la mediocridad social que Mill teme, la estandarización de la opinión pública. Lo que Mill observa es una sociedad dominada por la masa, una sociedad en la cual es difícil encontrar pasiones públicas relevantes, sea porque los hombres no participan activamente en el "espacio público" o bien prefieren quedar bloqueados en sus exigencias particulares, esclavos de la opinión dominante de la masa, y la masa, para Mill, terminará dominando al mundo (Ibídem). Mill percibe la masa como agobiante para el individuo que, a menudo, parece quedarse al margen en una condición de impotencia. "El individuo se encuentra perdido en la multitud"(Mill 1859).

El buen resultado de la política es producido, para nuestro autor, por una composición iluminada de visiones distintas, de mayoría y oposición, de conservación y progreso, una conciliación de opuestos que puede ser mediada por posiciones distintas:

En política ya es casi un lugar común, que un partido progresista y otro conservador son ambos necesarios para una vida política próspera hasta que uno u otro no hayan ampliado su horizonte mental para volverse un partido progresista y conservador al mismo tiempo, que sepa ver y distinguir lo que merece la pena cambiar y lo que merece la pena conservar. Cada uno trae ventaja de los defectos del otro: pero es su recíproca oposición la que hace que ambos permanezcan entre límites racionales (Mill, OL, 1859).

Mill se preocupa principalmente de la libertad individual, que en ningún caso debería ser oprimida por la mayoría y que en un sistema democrático jamás resuelve la cuestión. Al contrario, advierte que "donde la opinión pública es soberana, un individuo oprimido por el soberano, no encuentra, como en otras situaciones, otro poder rival al que pueda recurrir para obtener asistencia o al menos solidaridad (sympathy)" (Mill 1848). La mayoría de la que se produce la opinión pública acaba nivelando hacia abajo la sociedad $\mathrm{y}$, en su contra, el individuo no puede confiar en una alternativa de escape, pues la opinión dominante de la mayoría termina esclavizando al individuo.

La oposición, para evitar la tiranía de la mayoría y el control último por parte del pueblo, es la base para el buen gobierno; y la forma de gobierno representativo, en teoría, permite ambas condiciones. Para Mill "gobierno representativo significa que la nación o al menos una porción numerosa de ella, ejerza por medio de diputados que nombra periódicamente, el poder supremo de inspección e intervención (...) La nación debe poseer este poder en el sentido más absoluto de la palabra. (...) No es necesario que la Constitución le dé este imperio" (Mill 1985, p. 54). El poder del pueblo entonces prescinde de la forma de gobierno, se trata de una garantía contra el abuso; esta parece la razón por la cual Mill especifica que se trata de un poder de control, unido a un poder 
de destitución, en el caso de que se considere inapropiada la actividad política de los representantes para prevenir los sinister advantage o sinister interests (Mill 1826) ${ }^{20}$.

Sin embargo, Mill no parece tener una confianza incondicionada sobre la actividad de los diputados, por esto advierte que la experiencia demuestra que los depositarios del poder que son delegados por el pueblo, por la mayoría del pueblo, están dispuestos (cuando piensan poder confiar en el apoyo del pueblo, igual que cualquier otro órgano de una oligarquía) a emplear poderes arbitrarios e intervenir ilegítimamente en la esfera privada de los ciudadanos (Ibídem).

Para Mill, lo normal es que el poder material (wordly power) venga ejercido por las personas más competentes (fittest persons) y esto se da en el estado natural de una sociedad política cuando el interés de la colectividad es el mismo interés de las instituciones, lo cual depende del grado de progreso cultural de una sociedad: cuanto más desarrollada y políticamente activa sea una sociedad, tanto más adecuadas serán las instituciones que se formarán en ella: "Recordemos, en primer lugar, que las instituciones políticas (...) son obra de los hombres, que deben su origen y toda su existencia a la voluntad humana. (..) así pues como todas las cosas debidas al hombre pueden estar bien o mal hechas" (Mill 1985). La advertencia de Mill es que las instituciones políticas dependen del grado de progreso de una sociedad. Los gobiernos actúan y funcionan como productos de la voluntad humana y pueden funcionar bien solo si la sociedad está educada e instruida para elegir el camino del bienestar colectivo ${ }^{21}$.

\section{Conclusiones}

1. El concepto de bien común, al que tanto se refiere J. S. Mill en este ámbito, ha sido criticado por su abstracción: ¿qué es el bien común? ¿Cómo se puede determinar en concreto? Sobre todo, ¿cuáles son los criterios para determinar quiénes tienen la capacidad de decidir sobre el bien común? En efecto, la cuestión atávica sobre la representación política no puede no tener en consideración el elemento del bien común. Para encuadrar lo que es el bien común es necesario, ante todo, explicar lo que el bien común no es. En otras palabras, el bien colectivo se encuentra donde no

Mill comenta y reseña un ensayo de Samuel Bailey intitulado "Rationale of political representation" y reporta las palabras del filósofo: "Un representante es un delegado del pueblo, encargado para hacer lo que el pueblo no puede hacer directamente y está determinado, en sus acciones, a tener en cuenta el bien público puesto que el pueblo tiene el poder de destituirlo de su cargo" (Mill 1835).

21 Para Dalmacio Negro Pavón, la teoría política de Mill es el "triunfo de los ideales del gobierno de minorías cualificadas por su saber, aisladas en su labor de la masa de los gobernados, a quienes es inasequible la complicada maquinaria administrativa. El Estado que "marcha por sí sólo" pretendidamente desideologizado, despolitizado, ha sido, a la larga, la consecuencia de las convicciones de Mill a favor del economismo y del cientifismo y de un cierto hedonismo resignado" (Negro Pavón 1968, p. 143). 
hay espacio para intereses particulares. Sin embargo, este modelo imaginado por Sieyès es más fácil de teorizar que de poner en práctica, a la luz de una realidad basada en el poder. Es difícil complementar el poder con el interés general y suponer que el representante permanezca inmune a la fuerza del poder. Mill considera que el representante del pueblo debe tener en cuenta solo el interés general de la comunidad. Pero es muy consciente de la dificultad de clasificar lo que constituye el bienestar social; en efecto, si se pudiera concordar que uno de los aspectos del bienestar colectivo es el progreso de la sociedad en el sentido de su constante mejora, más dudas caben sobre otro aspecto considerado fundamental: el orden. Si entre las tareas de un buen gobierno entra su capacidad de hacerse obedecer, Mill señala que la obediencia es solo un instrumento y no el fin del gobierno; el gobierno necesita lograr obediencia para lograr el progreso. Ahí se nota una vez más el matiz liberal de Mill, que trata de limitar la acción de gobierno que tiene que permanecer exclusivamente al servicio de la sociedad.

2. Con respecto a la dicotomía mayoría-minoría, Mill propone cambiar el sistema electoral por el modelo proporcional formulado por Hare. El concepto de minorías en Mill tiene un doble significado: por una parte, la minoría entendida como todos los individuos que no están representados en el Parlamento y, por otra parte, la minoría entendida como elites, como la clase culta (en el sentido orteguiano), que debe de aportar su talento en provecho de la nación. La verdadera democracia para Mill no es otra cosa que la representación de todos los individuos "hombre por hombre"; considerando que el sistema representativo sea un sistema adecuado, el filósofo se preocupa de mejorarlo con el método Hare para que la mayoría numérica se convierta en "mayoría proporcional". En efecto, Mill cree en la democracia, pero se preocupa de que ésta degenere no en una dictadura de la mediocridad y, para impedirlo, la clave es que las minorías estén adecuadamente representadas.

3. La cuestión de moralidad constitucional sobre la esencia del mandato representativo subraya una posición intermedia de Mill que no se decanta ni por los principios formales de autorización, con el consecuente mandato en blanco, ni tampoco por los principios clásicos del mandato imperativo. La "tercera vía" de la metapolítica milliana propone un representante libre pero responsable, atento a las opiniones y a las aspiraciones de los representados, pero al mismo tiempo capaz, competente y autorizado a distanciarse de las opiniones de los electores cuando éstas no se ajusten al interés nacional. El poder de control al que Mill se refiere es la garantía contra el abuso de los gobernantes. El Parlamento no es la institución más adecuada para tomar decisiones, al Parlamento compete aprobar las decisiones tomadas por el gobierno. Los representantes tienen entonces una función de control y crítica de la conducta del gobierno.

4. Mill estudia la democracia no como una forma política sino "como expresión de un modo de vida posible" (Negro Pavón 1969, p. 133). Analizando argumentos e influencias distintas el pensador inglés quiere dar forma a un estilo de vida democrático hacia el cual todos los individuos tienen que estar educados. Efectivamente para Mill la democracia es un estadio del desarrollo humano. La verdadera democracia 
se sustenta en la representación de todos; al contrario, la falsa democracia es la representación de la mayoría.

5. Expuesta una serie de reflexiones racionales sobre la democracia y el sistema representativo, Mill no parece profundizar los conceptos con correctivos jurídicos relevantes. Si por un lado advierte sobre la imposibilidad de que exista una real coincidencia entre gobernantes y gobernados, puesto que el pueblo que ejerce el poder no es siempre el pueblo sobre quien se ejerce, por otro lado se limita a indicar el sistema proporcional y la educación junto a una acción pedagógica de un gobierno formado por una minoría selecta, como soluciones de todos los puntos críticos de la representación política.

\section{Referencias bibliográficas}

Bluntschli J. J. (1880), Derecho Público Universal. Madrid: Góngora.

Bobbio N. (2003), Teoría general de la política. Madrid: Trotta.

Bockenforde E. W. (1985), "Democrazia e rappresentanza", Quaderni costituzionali, a. V, n. 2, agosto 1985 .

Burdeau G. (1955), "Situación de la democracia pluralista", Revista de Estudios Políticos n. 82.

Burke E. (1993), Reflexiones sobre la Revolución francesa. Madrid: Alianza.

Constant B. (1988), Del espíritu de la conquista. Madrid: Tecnos.

(1989), Escritos políticos. Madrid: Centro de Estudios Constitucionales.

Dahl R. (2000), La poliarquía. En VVAA, Diez textos básicos de ciencia politica. Barcelona: Ariel.

Galvao de Sousa (2011), La representación política. Madrid: Marcial Pons.

Guizot F. (1839), Historia general de la civilización en Europa. Barcelona: Oliveres y Gavarró.

Jiménez Sánchez J. J. (2004), “La democracia limitada de J. S. Mill”, John Stuart Mill y las fronteras del liberalismo. Granada: Manuel Escamilla Castillo.

Kelsen H. (1934), Esencia y valor de la democracia. Barcelona-Buenos Aires: Labor. (1958), Teoría general del derecho y del Estado. México: Universidad Nacional Autónoma de México.

Manin B. (1998), Los principios del gobierno representativo. Madrid: Alianza.

Mill J. S. (2005), "Tocqueville sulla democrazia in America", L'America e la democrazia. Milano: Bompiani, p. 257.

(1977), De Toqueville on democracy in America, The Collected Works of John Stuart Mill, Essays on politics and Society. Toronto: Liberty Found, en http://oll.libertyfund.org/titles/165

(1826), The British Constitution.

(1832), Pledges, Examiner (P). 
(1832), Use and abuse of political terms (UA). (1840), De Toqueville on democracy in America.

(1845), Guizot's Essays and Lectures on History. (1848), Principles of political economy.

(1859), On Liberty, (OL).

(1859), Thoughts on parliamentary reform, (TOPR)

(1862), Centralisation.

(1985), Del gobierno representativo. Madrid: Tecnos.

(1999), La libertà, l'Utilitarismo, l'asservimento delle donne. Milano:

Rizzoli.

(1999), Bentham e Coleridge. Napoli: Guida editori.

Negro Pavón D. (1969), "El Liberalismo de Alexis de Tocqueville y de John Stuart Mill”, Revista de estudios políticos n. 167.

(1985), Comte: Positivismo y revolución. Madrid: Cincel.

Ortega y Gasset J. (1983), Obras Completas. Madrid: Alianza.

(1908), De re política. Tomo X.

(1922), España invertebrada. Tomo III

(2011 ), La rebelión de las masas. Madrid: Espasa.

Pitkin H. F. (1985), El concepto de representación. Madrid: Centro de Estudios Constitucionales.

Sartori G. (2011), Democrazia cos'è. Milano: BurSaggi Rizzoli.

Shumpeter J. A. (1971), Historia del análisis económico. Barcelona: Ariel.

Sieyes E. J. (1991), ¿Qué es el Tercer Estado? Ensayo sobre los privilegios. Madrid: Espasa Calpe.

Tocqueville A. (1988), L'Ancien Régime et la Revolutión. Paris: Flammarion. (1990), La democracia en América. Madrid: Aguilar.

Urbinati N. (2006), L'ethos della democrazia. Mill e la libertà degli antichi e dei moderni. Roma-Bari: Laterza. 